\title{
The Use of Linear Programming for Determining Number of Fire-Fighters on Shifts in Case of Special Events
}

\section{Obrad Stevanović ${ }^{1}$, Dalibor Kekić ${ }^{1}$, Valentin Kónya ${ }^{2}$, Miloš Milenković ${ }^{3}$}

\author{
${ }^{1}$ Academy of Criminalistic and Police Studies, Department of Police Sciences, \\ Cara Dušana 196, 11080 Zemun, Belgrade, Serbia \\ ${ }^{2}$ Faculty of Economics, University of Novi Sad, Segedinski put 9-11, 24000 \\ Subotica, Serbia \\ ${ }^{3}$ University of Belgrade, Faculty of Organizational Sciences, Jove Ilića 154, \\ 11000 Belgrade, Serbia \\ obrad.stevanovic@kpa.edu.rs, dalibor.kekic@kpa.edu.rs, valentink@uns.ac.rs, \\ mijatov51804@fon.bg.ac.rs
}

\begin{abstract}
This paper focuses on finding the most suitable number of fire-fighters who will be engaged on special events, such as concerts, sport tournaments, music events or similar events, while at the same time ensuring the number of fire-fighters in a particular fire station for each shift will be enough to ensure the overall social welfare of a community and remain at the lowest possible costs. Due to the risk of fire and other public welfare risks, it is often common fire-fighters are required to be engaged in special events with their duty primarily at those special event locations. Their main task certainly is to protect all people in a community and its assets by quick response in case of an emergency. Consequently, it remains necessary to provide a sufficient number of fire-fighters who will remain at the fire station so that they meet the standard requirements of them during each shift. In cases of temporary absences and permanent attrition in the fire-fighter workforce, sometimes commanders need to use overtime and hiring of additional fire-fighters to satisfy the needs of organizers of special events. In those situations, they also have to think about minimizing total staffing costs and budget restraints. This paper uses linear programming to develop a model for determining the optimal number of fire-fighters to have on staff during additional demands of special events still covering the standard emergency coverage within a community. Also, the aim of this paper is to present a model which will facilitate the decisions of commanders of fire stations when determining the number of fire-fighters required for ordinary and extraordinary activities.
\end{abstract}

Keywords: fire-fighter; model; constraints; optimization 


\section{Introduction}

Disasters are appearing more and more often in our world than ever before. They cause victims and also a huge amount damages in many areas of life, e.g. energy distribution, flow of transportation and logistics, health care demands, availability of education, financial costs, housing and many others. Despite overwhelming disasters, every day events happen such as fires, explosions and other similar day to day tragedies. In all cases the main emergency forces protecting and rescuing the public during these occurrences are our fire-fighters. Statistics shown in the large number of calls, which they receive for assistance on a daily basis, around the world, speak enough about their great contribution to society and the phenomenal demands placed on them.

Looking at the history and development of the fire service, in its early stages individuals were primarily part of the service as volunteers. However, as the requirements of the profession became more sophisticated and the volume of calls increased, it became necessary to employ qualified, full-time, well-trained firefighters $[1,16]$. Production development, new technologies, as well as climate change, created a growing number of risks that endangered people, material and cultural assets. In connection with this fact, those influences on society created increases in the need for and engagement of professional fire-fighters in our communities. However, as most often happens the number of fire-fighters has not kept up with the growth of those influences.

In addition to the regular requirements of community protection, care and welfare of citizens and their property in the event of social and special events fire-fighters are needed to be present at them in official capacity. Sport games and competitions, music events, visits of foreign statesmen and similar, are examples of the previously mentioned events. So, the Fire Station Commanders and Emergency Coordinators have to make decisions of the number of fire-fighters that will be engaged in those special events and at same time what manpower will remain in the fire station covering routine emergency standby requirements. These management personnel in many cases have difficult decisions to make when deciding on the appropriate number of engaged fire-fighters, most especially when comparing the workload to the number of available personnel.

One of the limiting conditions is that those workers may not work constantly because of "Occupational Health Risk Limitations" which are required due to the exposures and hazards found within the work environment. Usually, fire-fighters work during two shifts as is the case with fire service in the Republic of Serbia. After a daily shift of 12 hours, which starts at 7 am and finishes at $7 \mathrm{pm}$ they have a break of 12 hours. The opposite shift, which starts at $7 \mathrm{pm}$ and finishes at 7 am has a break of 24 hours. So, in case of a special event and with a limited number of staffed fire-fighters it is not so easy to make the right decision which number of them will be can be assigned considering the restrictions that apply within the work-rest cycle. Another consideration is connected to the costs of additional engagement of fire-fighters. Fire-fighters are, generally, officers of some governmental institution, for example Ministry of Interior or Directorate for 
Emergency Situations. In times of economic crisis, the budget of the state institutions is quite limited. Most often Commander of Fire Stations can deploy only that additional number of fire-fighters, in case like special events, which is consistent with the assigned budget. By linear programming, we can define a model with the previously mentioned constraints. This can help in determining the optimal number of engaged fire-fighters for any given shift, of whom part may be allocated to the special event.

\section{Theoretical Background}

During the last two decades, a great number of models that solve problems connected with determining number of security forces have been developed. However, the use of linear programming in this sense mostly is directed towards the police force. Taylor and Huxley [2] developed a police patrol scheduling system (PPSS). Currently, this system is used by all San Francisco (SF) police precincts which use PPSS to schedule all of their officers. It is estimated that PPSS saves the SF police more than \$5 million annually. This system, especially, proved to be beneficial when it was used for planning the required number of personnel and additional requirements for hiring for concerts, sporting events or rallies.

In the last decade a large number of authors have dealt with the theme of optimizing the number of operational forces that are required to react in case of an emergency events or situation. Also, some of them were focused on developing the most appropriate model for determining the number of fire-fighters which are required for just one shift to satisfy all the demands of a local society. So, some of them use stochastic models based on the queuing theory. Although the operation of the fire stations, as an example of one unit intended for reacting in cases of emergencies, is very complex, many researchers try to focus on the most important parts of the staff process and build simpler stochastic queuing models to study the problem of staffing. These models strive to seek a balance between tractability and validity and obtain some very valuable results [3, 4-6].

When defining the model, significant attention of some research is paid to financial constraints in hiring of additional numbers of fire-fighters, as is the case of during special events. Fry, Magazine and Rao [7] examine the problem of determining the annual staffing level that minimizes total expected costs for a fire department, subject to minimum service-level-based staffing requirements. They develop a quantitative model that allows for stochastic temporary absences, permanent wastage, and limited hiring opportunities, which takes into account the unique fire-fighter work schedule.

Thesis about optimizing fire department operations through work schedule analysis, alternative staffing, and non-productive time reduction, done by the Naval postgraduate school [8], conducts a policy analysis exploring how current fire department policies can be modified to optimize employee availability to lead 
to higher staffing levels and lower sick leave and injury leave usage. Work schedule modification and alternative staffing models are the two options examined in this thesis. Also, many authors try to evaluate different shift work systems in a rigorous, controlled environment, using measures relevant to the cognitive demands of incident management and firefighting [9].

\section{Methodology}

In this paper, the model for finding the optimal number of fire-fighters required on shifts during special events is suggested. Many constraints affect defining the optimal number of fire-fighters in those situations. The most influential constraint is the minimal requested number of fire-fighters which are needed by organisers of special events, such as: musical concerts, sport matches and the similar. On the other hand, based on risk assessments or statistical data of the fire station what each shift commander requires to satisfy the minimal number of professionals who are engaged. Also, a limiting factor should be the budget of fire service. In a times where all state institutions have limited available funds, all issues and costs of support must be taken into account when adding additional manpower to the workforce. Another, interesting question and at same time limiting factor for leaders and managers when making decisions about the number of engaged firefighters, is what to do in case of vacations or employee absence due to sick leave. Linear programming is used for minimization of engaged fire-fighters per a single shift from which part of the manpower will be sent to a special event. All mentioned constraints are taken into account during model definition.

\subsection{Model Definition}

In order that the commander of the fire station make the right decision concerning the number of fire-fighters in one shift during special events, with minimal costs, the model has to be correctly defined with all real constraints [15]. Firstly, this problem should only occur when organiser of special event has a legal obligation to have a fire-fighter on site or they recognize a need for them because of safety concerns. Usually, after a meeting between organizers and representatives of the security services, decisions will be made about necessary forces to be engaged. So, commanders of territorially competent fire station will receive the request for engagement of fire-fighters for that special event, in the form of an official letter sent by the organizers. Practice shows that on the basis of specific criteria, such as the expected number of spectators, time of day and experiences from previous similar events will be given and the minimum requirements for the number of firefighters present. An additional problem may be that there are unequal required numbers of fire-fighters during different periods of time during the event. The main part of the letter sent to the fire station should provide this information in table form. 
Table 1

Example of table form of the required number of fire-fighters

\begin{tabular}{|l|l|}
\hline Time period of special event & The minimal number of fire-fighters \\
\hline Time period 1 & $\mathrm{n}_{1}$ \\
\hline Time period 2 & $\mathrm{n}_{2}$ \\
\hline Time period $\mathrm{n}$ & $\mathrm{n}_{\mathrm{i}}$ \\
\hline
\end{tabular}

In addition to the new taking the commander of the fire station has an obligation to provide a sufficient number of fire-fighters who will be at the fire station ready for action during the ordinary and extraordinary circumstances. Most fire departments around the world are organized to operate in two shifts that last twelve hours. For the purposes of this paper such a mode will be taken into account.

Table 2

Review of shift duration and minimal number of fire-fighters per one shift

\begin{tabular}{|l|l|l|l|}
\hline Shift & Shift start & Shift end & $\begin{array}{l}\text { Minimal number of fire-fighters per } \\
\text { shift }\end{array}$ \\
\hline 1 & Time1 & Time2 & $\mathrm{N}_{1}$ \\
\hline 2 & Time2 & Time1 & $\mathrm{N}_{2}$ \\
\hline
\end{tabular}

We want to minimize the total number of fire-fighters scheduled, for a special event and also for the fire station, so the model will be defined as follows:

$\min f(x)=x_{1}+x_{2}$

subject to:

$x_{1} \geq n_{i}$

$x_{2} \geq n_{i}$

$x_{1}+x_{2} \geq n_{i}$

$x_{1} \geq N_{1}$

$x_{2} \geq N_{2}$

$x_{1}, x_{2} \geq 0$

where $\mathrm{x}_{1}$ is the number of fire-fighters who will work in the first shift, and $\mathrm{x}_{2}$ is the number of fire-fighters who will work in the second shift.

The objective function (1) is to minimize the total number of engaged fire-fighters on both shifts. Constraint (2) shows the total number of fire-fighters on the first shift have to be more or equal to the required number of them in the time period $i$ $(i=1,2 \ldots$, the last time period) of the special event. It is important to mention that organizers usually have different demands for fire-fighters during different time periods of a special event. For example, organizers of the New Year celebration divide the whole celebration into different periods and based on mentioned criteria 
define different numbers of fire-fighters needed for a certain periods of time. It is clear that the number of fire-fighters on the first shift will be limited to the required minimum for the period of special events that fall under the first shift. Constraint (3) shows the total number of fire-fighters in the second shift have to be more or equal to the required number of them during the time period $i(i=1,2 \ldots$, the last time period) of the special event. Also, the number of fire-fighters on the second shift will be limited to the required minimum for the period of the special events that fall under the second shift. Constraint (4) shows that in the case that a certain period of time of the special event refers to both shifts the total number of fire-fighters in shifts must meet the required minimum number of fire-fighters during this period. Constraint (5) points that the number of fire-fighters in the first shift have to be more or equal to the minimal number of fire-fighters per that shift. The same applies to constraint (6), only it relates to the second shift. Practice shows that on the basis of certain standards each shift requires a certain number of fire-fighters. Also, risk assessment is a very useful tool for determining those standards. Additionally, the number of fire-fighters that are needed for each shift may vary according to time of year, from natural and environmental and other disasters issues. The warnings and regulations are established and given by competent authorities concerning the possible dangers. In many countries around the world specific policies and guidelines precisely define the numbers of firefighters for each shift. An example of this is in the United States of America where the National Fire Protection Association (NFPA) publishes standards for fire departments to use a guide. Although they are not required to follow, the publications often become the way of conducting business in the fire service. The NFPA Index was examined for standard(s) of recommended numbers of firefighters when performing fire ground operations or as required number per shift [10]. For adequate determination of numbers $\mathrm{N}_{1}$ and $\mathrm{N}_{2}$, which will be used for constraints, can serve as standards for the required number of fire-fighters by population protected. European Union norms envisaged that per every 1,000 inhabitants a country must have at least one fire-fighter [11]. As usual, the nonnegative constraint (7) completes the formulation.

In some cases, the objective function of the mathematical model and the standard of scheduling will result in the least expenditures of the daily budget and not reduce the normal levels of employees. This may lead to a change of the objective function and that may lead to a change to the optimal solution. The commander of a fire station that is responsible for determining the number of fire-fighters is well acquainted with the fact that daily allowances which would be utilized to engage fire-fighters on the second shift are larger than daily allowances of fire-fighters who work during the first shift. In accordance with this and in a situation of where you have limited funds it is sometimes necessary to include this criterion in defining the mathematical model. What Fred McChesney wrote some 10 years ago is even more true today that taxpayers are unlikely to support budget increases for fire departments if they see inactive firemen lolling about the fire station [12]. So, cities have created new, highly visible jobs for their firemen. The Wall Street Journal reported recently, "In Los Angeles, Chicago and Miami, for example, 90\% of the emergency calls to firehouses are to accompany ambulances to the scene of 
auto accidents and other medical emergencies. Elsewhere, to keep their employees occupied, fire departments have expanded into neighbourhood beautification programs, gang intervention, substitute-teaching and other non-firefighting pursuits." [13]. So, the engagement of fire-fighters with special events can certainly be adequate to justify their manpower numbers at fire stations, but in determining the manpower levels financial costs must be taken into account. When we know the amount of daily allowance for hiring fire-fighters, to the first, and the second shift model, we can have the following form:

$\min f(x)=C 1 \cdot x_{1}+C 2 \cdot x_{2}$

where $\mathrm{x}_{1}$ still is the number of fire-fighters who will work in the first shift, and $\mathrm{x}_{2}$ is the number of fire-fighters who will work in the second shift. The objective function (8) is to minimize the total cost of engaged fire-fighters in both shifts. Constraints (2-7) in this case the same form remains. $C_{1}$ is the value of cost for the daily allowance for one fire-fighter on the first shift, while $\mathrm{C}_{2}$ is the value of cost for the daily allowance for one fire-fighter on the second shift. Those values are not same because value $\mathrm{C}_{2}$ has to be bigger than the first one as it refers to night shift which according to existing regulations requires a higher fee.

The duties of a fire-fighter carries with them certain risks, which often have a negative impact on their health. Inherent in working for the fire service or emergency services is the requirement to work a shift schedule that includes nights, a determined health risk. The challenge for administrators is to provide the necessary level of service to the community while recognizing that night work has consistently been recognized as a serious risk factor for workers' health as it interferes with our basic biological functions, social relations, and psychological/mental health [1]. All those indicate the possible absence of firefighters due to health problems. Also, the interventions of fire-fighters are often performed in difficult conditions and injuries at work are common. Also, firefighters may be absent from work due to vacation days that they normally earn and acquire. In connection with the previously mentioned appears an additional constraint which is:

$x_{1}+x_{2} \leq N$

where, in addition to the above described variables $\mathrm{x}_{1}$ and $\mathrm{x}_{2}, \mathrm{~N}$ is total number of available fire-fighters on which the commander of a fire station can rely, including all absent.

\section{Results}

This research is based on a fire station whose number of employed fire-fighters, according to the standards of the European Union, serve a populated area of about 50,000 inhabitants and which received from organizers of a celebration of a New Year special event a request for engaging fire-fighters at various different 
locations. In this paper, taking into consideration that mentioned constrains are relevant for making decision about the optimal number of engaged fire-fighters, we summarized criteria from previous studies in this area, as the outcomes of the literature review, in order to more precisely understand the influence of demands for additional commitment arising out of special events to make right decisions of manpower. Finally, tables shown in the following part of the paper represent the application of dual model as a method of linear programming.

At the beginning of the case study it should be noted that the organizers of the New Year celebrations had already determined, based on the experience of previous years, how many fire-fighters were necessary to protect different areas in the period of 7.00 am on $31^{\text {st }}$ December to 7.00 am on $1^{\text {st }}$ January. They found, that the number of needed fire-fighters depends on the time of day as shown in Table 3.

Table 3

Required number of fire-fighters

\begin{tabular}{|l|l|}
\hline New Year celebrations time period & Minimal number of fire-fighters \\
\hline 7 am $31^{\text {st }}$ December $-4 \mathrm{pm} 31^{\text {st }}$ December & 5 \\
\hline $4 \mathrm{pm} 31^{\text {st }}$ December $-24: 0031^{\text {st }}$ December & 8 \\
\hline $0: 001^{\text {st }}$ January -7 am $1^{\text {st }}$ January & 12 \\
\hline
\end{tabular}

Fire-fighters from this fire station work in shifts as is shown in the table below. It should be pointed out that third shift is the inter-shift or spare shift that in some situations is inserted into the manpower scheme as the need arises, and the first two shifts are standard shifts.

Table 4

Shift duration

\begin{tabular}{|l|l|l|l|}
\hline Shift & Shift start & Shift end & $\begin{array}{l}\text { Number of fire-fighters per shift as } \\
\text { variable of model }\end{array}$ \\
\hline 1 & $7 \mathrm{am}$ & $7 \mathrm{pm}$ & $\mathrm{x}_{1}$ \\
\hline 2 & $7 \mathrm{pm}$ & $7 \mathrm{am}$ & $\mathrm{x}_{2}$ \\
\hline 3 & $4 \mathrm{pm}$ & $4 \mathrm{am}$ & $\mathrm{x}_{3}$ \\
\hline
\end{tabular}

Initially, we should formulate a mathematical model of the given problem. Target function will be the minimization of the total number of engaged fire-fighters which will satisfied the order from organizers. The model would seem:

$\min f(x)=x_{1}+x_{2}+x_{3}$

subject to:

$x_{1} \geq 5$ required number of fire-fighters between 7 am and $4 \mathrm{pm}$

$x_{1}+x_{3} \geq 8$ required number of fire-fighters between $4 \mathrm{pm}$ and $7 \mathrm{pm}$

$x_{2}+x_{3} \geq 8$ required number of fire-fighters between $7 \mathrm{pm}$ and 24:00 
$x_{2}+x_{3} \geq 12$ required number of fire-fighters between 0:00 and 4 am

$x_{2} \geq 3$ required number of fire-fighters between 4 am and 7 am

$x j \geq 0 j=1,2,3$

Constraints in this model are in accordance with the required number of firefighters at the indicated time periods of the New Year celebrations and duration of the shifts. For determining the optimal solution, it is recommended solving through the dual model as a method of linear programming, which will be shown below.

$\max \varphi(y)=5 y_{1}+8 y_{2}+8 y_{3}+12 y_{4}+3 y_{5}$

subject to:

$y_{1}+y_{3} \leq 1$

$y_{3}+y_{4}+y_{5} \leq 1$

$y_{2}+y_{3}+y_{4} \leq 1$

$y i \geq 0 i=1,2,3,4,5$

$\max \varphi(y)=5 y_{1}+8 y_{2}+8 y_{3}+12 y_{4}+3 y_{5}+0 \cdot\left(j_{1}+j_{2}+j_{3}\right)$

subject to:

$y_{1}+y_{3}+j_{1}=1$

$y_{3}+y_{4}+y_{5}+j_{2}=1$

$y_{2}+y_{3}+y_{4}+j_{3}=1$

$y i \geq 0 i=1,2,3,4,5$

Table 5

$\mathrm{T}_{0}$ of dual model

\begin{tabular}{|c|c|c|c|c|c|c|c|c|c|c|c|}
\hline \multicolumn{2}{|c|}{} & 5 & 8 & 8 & 12 & 3 & 0 & 0 & 0 & \multirow{2}{*}{$\begin{array}{c}\text { CFA/ } \\
\text { Cb }\end{array}$} \\
\begin{tabular}{c|c|c|c|c|c|c|c|c|c|c|c|c|c|c|c|} 
Bas \\
e
\end{tabular} & CFA & $\mathrm{y}_{1}$ & $\mathrm{y}_{2}$ & $\mathrm{y}_{3}$ & $\mathrm{y}_{4}$ & $\mathrm{y}_{5}$ & $\mathrm{j}_{1}$ & $\mathrm{j}_{2}$ & $\mathrm{j}_{3}$ & \\
\hline$\leftarrow 0$ & $\mathrm{j}_{2}$ & 1 & 1 & 1 & 0 & 0 & 0 & 1 & 0 & 0 & - \\
\hline 0 & $\mathrm{j}_{3}$ & 1 & 0 & 1 & 1 & 1 & 0 & 0 & 0 & 1 & 1 \\
\hline \multicolumn{2}{|c|}{$-\mathrm{f}$} & 0 & 5 & 8 & 8 & 12 & 3 & 0 & 0 & 0 & \\
\hline
\end{tabular}


Table 6

$\mathrm{T}_{1}$ of dual model

\begin{tabular}{|c|c|c|c|c|c|c|c|c|c|c|c|}
\hline \multicolumn{2}{|c|}{} & 5 & 8 & 8 & 12 & 3 & 0 & 0 & 0 & CFA/ \\
\cline { 1 - 11 } $\mathrm{Cb}$ & Base & CFA & $\mathrm{y}_{1}$ & $\mathrm{y}_{2}$ & $\mathrm{y}_{3}$ & $\mathrm{y}_{4}$ & $\mathrm{y}_{5}$ & $\mathrm{j}_{1}$ & $\mathrm{j}_{2}$ & $\mathrm{j}_{3}$ & $\mathrm{y}_{2}$ \\
\hline 0 & $\mathrm{j}_{1}$ & 1 & 1 & 1 & 0 & 0 & 0 & 1 & 0 & 0 & 1 \\
\hline 12 & $\mathrm{y}_{4}$ & 1 & 0 & 0 & 1 & 1 & 1 & 0 & 1 & 0 & - \\
\hline$\leftarrow 0$ & $\mathrm{j}_{3}$ & 0 & 0 & $\underline{\mathbf{1}}$ & 0 & 0 & -1 & 0 & -1 & 1 & 0 \\
\hline \multicolumn{2}{|c|}{$-\mathrm{f}$} & -12 & 5 & 8 & -4 & 0 & -9 & 0 & -12 & 0 & \\
\hline
\end{tabular}

$\uparrow$

Table 7

$\mathrm{T}_{2}$ of dual model

\begin{tabular}{|c|c|c|c|c|c|c|c|c|c|c|c|}
\hline \multicolumn{2}{|c|}{} & 5 & 8 & 8 & 12 & 3 & 0 & 0 & 0 & CFA/ \\
\hline $\mathrm{Cb}$ & Base & CFA & $\mathrm{y}_{1}$ & $\mathrm{y}_{2}$ & $\mathrm{y}_{3}$ & $\mathrm{y}_{4}$ & $\mathrm{y}_{5}$ & $\mathrm{j}_{1}$ & $\mathrm{j}_{2}$ & $\mathrm{j}_{3}$ & $\mathrm{y}_{1}$ \\
\hline$\leftarrow 0$ & $\mathrm{j}_{1}$ & 1 & $\underline{\mathbf{1}}$ & 0 & 0 & 0 & 1 & 1 & 1 & -1 & 1 \\
\hline 12 & $\mathrm{y}_{4}$ & 1 & 0 & 0 & 1 & 1 & 1 & 0 & 1 & 0 & - \\
\hline 8 & $\mathrm{y}_{2}$ & 0 & 0 & 1 & 0 & 0 & -1 & 0 & -1 & 1 & 0 \\
\hline \multicolumn{2}{|c|}{$-\mathrm{f}$} & -12 & 5 & 0 & -4 & 0 & -1 & 0 & -4 & -8 & \\
\hline
\end{tabular}

$\uparrow$

Table 8

$\mathrm{T}_{3}$ of dual model

\begin{tabular}{|c|c|c|c|c|c|c|c|c|c|c|}
\hline & & & 5 & 8 & 8 & 12 & 3 & 0 & 0 & 0 \\
\hline $\mathrm{Cb}$ & Base & CFA & $\mathrm{y}_{1}$ & $\mathrm{y}_{2}$ & $\mathrm{y}_{3}$ & $\mathrm{y}_{4}$ & $\mathrm{y}_{5}$ & $\mathrm{j}_{1}$ & $\mathrm{j}_{2}$ & $\mathrm{j}_{3}$ \\
\hline 5 & $\mathrm{y}_{1}$ & 1 & 1 & 0 & 0 & 0 & 1 & 1 & 1 & -1 \\
\hline 12 & $\mathrm{y}_{4}$ & 1 & 0 & 0 & 1 & 1 & 1 & 0 & 1 & 0 \\
\hline 8 & $\mathrm{y}_{2}$ & 0 & 0 & 1 & 0 & 0 & -1 & 0 & -1 & 1 \\
\hline & & -17 & 0 & 0 & -4 & 0 & -6 & -5 & -9 & -3 \\
\hline & & & $\begin{array}{l}\uparrow \\
\mathrm{s}_{1}\end{array}$ & $\begin{array}{l}\uparrow \\
\mathrm{s}_{2}\end{array}$ & $\begin{array}{l}\uparrow \\
\mathrm{s}_{3}\end{array}$ & $\begin{array}{c}\uparrow \\
\mathrm{s}_{4}\end{array}$ & $\mathrm{~S}_{5}$ & $\begin{array}{c}\uparrow \\
\mathrm{x}_{1}\end{array}$ & $\begin{array}{c}\uparrow \\
\mathrm{x}_{2}\end{array}$ & $\begin{array}{c}\uparrow \\
\mathrm{x}_{3}\end{array}$ \\
\hline
\end{tabular}

From Table 8 we can read the result of solving our dual model. The results shown in the table is - 17 (-f). That number of fire-fighters is the minimum number required to satisfy the needs of the organizers of the New York celebration to cover all areas of the event. From them 5 would be on the first shift $\left(\mathrm{x}_{1}\right), 9$ on the second $\left(\mathrm{x}_{2}\right)$ and 3 fire-fighters on the third shift $\left(\mathrm{x}_{3}\right)$. At the same time, in the period between $7 \mathrm{pm}$ and 24:00 would be 4 more fire-fighters than is minimally necessary $\left(s_{3}\right)$. Also, in the period between 4 am and 7 am would be 6 additional fire-fighters than would be minimally necessary $\left(\mathrm{s}_{5}\right)$.

With those constraints in the primary model we should add additional constraints, such as those relating to limited financial resources when hiring fire-fighters. The commander of the fire station, who is responsible for determining the number of 
engaged fire-fighters analyses daily allowances which would be paid in salaries to both fire-fighters concludes that the manpower on the second and third shift have to be paid double the daily allowances than required on the first shift. Therefore, it is concluded that the criteria in the engagement of the fire-fighters should not be hiring fewer numbers, but to minimize the paid daily allowances. In this case there would be a change of the objective function. The new objective function is:

$$
\min f(x)=x_{1}+2 x_{2}+2 x_{3}
$$

However, in such a defined difference in wages there would not have been a change in the structure of the optimal solution. Change of the objective function of the primary model causes a change in the free member's limitations of the dual model. Solving the dual again will determine that all values in optimal base are nonnegative and that there is no change in the structure of the optimal solution.

Also, constraints relating to the minimum number of fire-fighters per shift also could influence the final results. Different standards or risk assessments are useful documents for defining those constraints which may be required to be modified or satisfied at any moment. So, for purpose of this part the paper emphasis is placed on constraints given by the organizers of special events. The same applies to the number of available fire-fighters in relation to the number of absent fire-fighters for various reasons. The solving procedure would be the same, only there would have been a larger number of constraints.

\section{Discussion}

The final results obtained in table 8 shows the aim of this research which was to obtain the required number of engaged fire-fighters per defined shift. These results are obtained on the basis of the defined mathematical model where the objective function minimization of total number of fire-fighters including constraints provided by the organizers of special event be defined in the case study.

According to this function and the constraints, which are used as part of one case study, the optimal solution of primal model is multiple because the optimal solution of the dual model is degenerated, respectively that in two periods of time there would be more fire-fighters than is necessary. By involving the constraints relating to the payment of daily allowances it can be seen that there are no changes in the optimal solution.

We can conclude that, through solving a mathematical model, decisions about the number of fire-fighters who will satisfy the requirements of the organizers of special events can be done in a more accurate way. Obtained results presented how different orders for engagement of fire-fighters with the goals of desired safety of all participants can be realized in very exact way. By implementation of the organizer's requirements into a mathematical model built up on the basis of linear programming, it is possible to make decisions more precisely. Final results 
achieved through solving a dual model are more accurate than some made only on the basis of previous experience.

What is frightening about these kinds of problems is that no matter how successful you have been in applying linear programming to solve problems, the next problem you confront may defy your best efforts to get a handle on it [14]. Probably, the "force-device" calculation model for determining the optimal number of fire-fighters on shifts in case of special events is not the simplest version. Commanders of fire stations in real practice have a lot of tasks to solve every day. Manual use of linear programming, without any software, for them will be very hard. Therefore, the desired solution would be to utilize an appropriate venue - "force-device" calculation model.

\section{Conclusion}

The goal of this paper is to recommend the use of linear programming when it is very difficult to make decisions about the right number of fire-fighters who will be present during a special event and at same time their maintaining their standard social requirements, working with limited financial resources and ensuring the safety of all citizens will not be jeopardized. A special part of this paper belongs to the practical use of linear programming which is shown through case study, and its implementation while determining the number of fire-fighters on shifts during particular special events. In making such decisions it is recommended that decision makers use this mathematical model to find the suitable solution. Some considerations are how difficult is it to train commanders of fire stations, which will be making these decisions, to use reality linear programming and the implementation that would follow. It is possible, but it is essential that this method be mastered by seasoned administrator of fire-fighters within the central part of state institutions before implementation. So, the requirements of organizers of special events will be submitted to the commander of a fire station who in turn will to involve the administrative evaluator (software user) who will utilize the model to analyze the requirements of manpower for any given event.

Also, a special computer program can be created for this purpose in connection with linear programming and our defined model. This software can be created to further obtain significant data in the over-all management of special events resulting in a very useful tool for the managers. This software, based on predefined constraints, would automatically solve the model and provide results with number of fire-fighters per each shift in case of special events and may also, provide statistical data and reports for use of the manager. LINDO and LINGO are examples of software products which can be useful base for making appropriate applications or probably sufficient for determining number of fire-fighters on shifts in case of special events.

\section{References}

[1] Cohen, I., and Plecas, D.: A Review of the Research Literature on 24-Hour Shifts for Fire-fighters, Centre for Public Safety and Criminal Justice Research, University of the Fraser Valley, 2015 
[2] Taylor, P., and Huxley, S.: A Break from Tradition for the San Francisco Police: Patrol Officer Scheduling Using an Optimization-Based Decision Support System, San Francisco, 1989

[3] Zeltyn, S., Marmor, Y. N., Mandelbaum, A., et.al.: Simulation-based Models of Emergency Departments: Operational, Tactical, and Strategic Staffing, ACM Transactions on Modeling and Computer Simulation, Vol. 21, No. 4, (2011)

[4] Green, L. V., Kolesar, P. J., Soares, J.: Improving the Sipp Approach for Staffing Service Systems that have Cyclic Demands, Operations Research, Vol. 49, No. 4, (2001) pp. 549-564

[5] Green, L. V., Soares, J., Giglio, J. F., Green, R. A.: Using Queueing Theory to Increase the Effectiveness of Emergency Department Provider Staffing, Academic Emergency Medicine, Vol. 13, No. 1, (2006) pp. 61-68

[6] Yom-Tov, G. B., and Mandelbaum, A.: Erlang-R: a Time-Varying Queue with ReEntrant Customers, in Support of Healthcare Staffng, Working Paper, Technion-Israel Institute of Technology, 2011

[7] Fry, M., Magazine, M., Rao,U.: Fire-fighter Staffing including Temporary Absences and Wastage, Operations Research, Vol. 54, No. 2 (2006) pp. 353-365

[8] Payne, J.: Optimizing Fire Department Operations through Work Schedule Analysis, Alternative Staffing, and Nonproductive Time Reduction, Naval postgraduate school, Monterey, 2014

[9] Short, M., et al.: Shift length: When less is more, Fire note, No. 120, 2014

[10] Monday, C.: Optimal Staffing Levels for Fire-Fighter Effectiveness and Mitigation of Fire-Fighter Injuries, Martinsville Virginia, 2000

[11] Government of the Republic of Serbia: Strategy of fire protection for the period 2012-2017, The Official Gazette of the Republic of Serbia, 2012

[12] Mc Chesney, F.: Smoke and errors, Library of economics and liberty, 2002

[13] Johnson, R.: As Blazes Get Fewer, Fire-Fighters Take on some Eclectic New Roles, The Wall Street Journal, 2001

[14] Kane, J.: The Art of Linear Programming, Professional Statistical Services, 2012

[15] Kónya, V., Grubić-Nešić, L., Matić, D.: The Influence of Leader-Member Communication on Organizational Commitment in a Central European Hospital, Acta Polytechnica Hungarica, Vol. 12, No. 3 (2015) pp. 109-128

[16] Kónya, V., Matić, D., Pavlović, J.: The Influence of Demographics, Job Characteristics and Characteristics of Organizations on Employee Commitment, Acta Polytechnica Hungarica, Vol. 13, No. 3 (2016) pp. 119138 